\title{
PENGEMBANGAN PARIWISATA BAHARI BERBASIS MASYARAKAT DI PULAU KALEDUPA, KABUPATEN WAKATOBI, PROVINSI SULAWESI TENGGARA (Community Based Marine Tourism Development in Kaledupa Island, Wakatobi Regency, South East Sulawesi Province)
}

\author{
Hadiwijaya Lesmana Salim* dan Dini Purbani \\ Pusat Penelitian dan Pengembangan Sumberdaya Laut dan Pesisir, \\ Balitbang Kelautan dan Perikanan-Kementerian Kelauatan dan Perikanan, \\ Komplek Bina Samudera, Jl. Pasir Putih 1 Ancol Timur Jakarta 14430. \\ *Penulis korespondensi. Tel: 021-64711583. Email: hadi2804@gmail.com.
}

Diterima: 9 Maret 2015

Disetujui: 23 Juni 2015

\begin{abstract}
Abstrak
Tujuan penelitian adalah mengetahui pengembangan pariwisata bahari berbasis masyarakat di Pulau Kaledupa dan sekitarnya, Kabupaten Wakatobi, Provinsi Sulawesi Tenggara. Penelitian dilakukan pada bulan Oktober - November 2014. Penelitian menggunakan metode analisis prospektif partisipatif, wawancara, analisis pengaruh antar-variabel kunci, membangun skenario, dan analisis implikasi strategis dan aksi antisipatif. Hasil penelitian menunjukkan bahwa terdapat tiga variabel utama yang harus dititikberatkan dalam pengembangan wisata bahari di Pulau Kaledupa dan sekitarnya, yaitu informatif, koordinasi antar instansi, dan sumberdaya alam. Penitikberatan pada ketiga variabel tersebut diharapkan dapat menghilangkan kesalahpahaman dan kesalahpenafsiran atas informasi yang diberikan sehingga dapat menunjang hubungan yang harmonis antar pemangku kepentingan pengembangan wisata bahari. Koordinasi yang harmonis diharapkan dapat mensinergikan antar perencanaan, pengembangan dan pengelolaan. Diharapkan pula sumberdaya alam yang ada berkesinambungan tanpa mengurangi dan merusak kualitasnya.
\end{abstract}

Kata kunci: ekowisata, masyarakat, pariwisata bahari, partisipatif, pulau kecil.

\begin{abstract}
The research on community based marine tourism development at Kaledupa island has been conducted on October - November 2014. This research used participatory prospective analysis, interview, Influence Analysis of inter key variables, scenario building, and Analysis of Strategic Implication and Anticipative act. The result shows that there are three key variables that should be focused on marine tourism development at Kaledupa island i.e informative, interinstitutions coordination, and natural resources. These variables should be focused in order to relieve misconception and misinterpretation on information which is given, so that it can support harmonic relationship between marine tourism stakeholders. The synergy of planning, development, and management can be expected from harmonic coordination. It is also expected that existing natural resources are sustainable without reducing and damaging the quality.
\end{abstract}

Keywords: community, ecotourism, marine tourism, participatory, small island.

\section{PENDAHULUAN}

Pasir, hutan mangrove, terumbu dan ikan karang di Pulau Kaledupa dan sekitarnya merupakan bagian dari kekayaan alam Kabupaten Wakatobi yang sebagian besar areanya berfungsi sebagai Taman Nasional Laut Wakatobi. Adam (2012) menyebut kawasan ini sebagai kawasan yang unik. Saat ini kawasan tersebut mulai terganggu dengan banyaknya wisatawan yang berkunjung. Data dari Balai Taman Nasional Wakatobi menyebutkan bahwa terjadi peningkatan jumlah wisatawan sebesar 14 kali lipat dari tahun 1996 hingga tahun 2010. Jumlah kunjungan wisata pada tahun 2008, sebanyak 1.395 tamu menginap pada penginapan di Kaledupa (Anonim, 2009). Para wisatawan tersebut biasanya memanfaatkan wilayah pesisir dan laut Wakatobi secara langsung maupun tidak langsung. Kegiatan langsung di antaranya berperahu, berenang snorkeling, menyelam, dan memancing. Kegiatan tidak langsung seperti kegiatan olahraga pantai, piknik menikmati atmosfer laut.

Masalah pariwisata bahari yang terjadi di Kabupaten Wakatobi di antaranya adalah belum optimalnya potensi pengembangan pariwisata mengingat Kabupaten Wakatobi memiliki keindahan pemandangan, keunikan alam, karakteristik ekosistem, kekhasan seni budaya dan karakteristik masyarakat. Khusus untuk Pulau Kaledupa, terdapat keunikan ekosistem yang lebih baik dibanding pulau lain di Wakatobi yaitu 
ekosistem mangrove (Febriani, 2011). Daya tarik utama di Pulau Kaledupa adalah keindahan alam yang harus dijaga dan dilestarikan yang dapat memberikan nilai tambah sebagai destinasi utama. Pengembangan pariwisata bahari perlu diperhatikan kelestarian lingkungan, peningkatan kesejahteraan masyarakat, terpenuhinya kepuasan pengunjung dan peningkatan keterpaduan dan kesatuan pembangunan masyarakat di sekitar kawasan pengembangan.

Beberapa metode kajian pengembangan pariwisata berbasis masyarakat telah dilakukan. Nugraha dan Aliyah (2013) menggunakan metode analisis interaktif dan analisis lingkungan internaleksternal di Karanganyar. Begitu juga dengan Sukadi dkk., (2013) yang menggunakan pendekatan etnografi di Bali. Sebagian besar metode analisis dilakukan secara deskriptif kualitatif seperti yang dilakukan oleh Tanaya dan Rudiarto (2014), Barus dkk., (2013) dan Harun (2014). Penelitianpenelitian tersebut tidak menentukan variabel kunci dalam pengembangan pariwisata yang memfokuskan pada pelibatan stakeholders. Sebagai bagian dari suatu pengembangan pariwisata bahari, aspek stakeholders dalam perencanaan harus dilibatkan dan dilakukan secara efektif.

Penelitian ini ingin mengetahui parameter variabel kunci dalam pengembangan pariwisata bahari di Pulau Kaledupa dan sekitarnya. Penentuan varibel kunci diperoleh dari hasil analisis prospektif partisipatif dengan para stakeholders dan masyarakat setempat. Analisis prospektif partisipatif, merupakan pendekatan yang mengedepankan proses partisipatif dan mampu memberikan kesepakatan (konsensus) antar stakeholder (Godet dan Roubelat 1996; Bourgeois dan Jesus 2004; Gray dan Hatchard. 2008). Dengan demikian pelibatan stakeholders dalam pengembangan pariwisata bahari secara substansial dapat dilakukan.

Tujuan penelitian adalah untuk mengetahui keterlibatan stakeholders dalam penentuan variabel kunci perencanaan, pendefinisian kondisi (states) variabel di masa datang, pembangunan skenario perencanaan, serta penyusunan implikasi strategis dan aksi antisipatif dalam pengembangan pariwisata bahari variabel kunci pengembangan pariwisata bahari di Pulau Kaledupa dan sekitarnya.

\section{METODE PENELITIAN}

\section{Waktu dan Lokasi Penelitian}

Survei dilaksanakan dari tanggal 31 Oktober-2 November 2014 di Pulau Kaledupa dan sekitarnya, Kabupaten Wakatobi, Provinsi Sulawesi Tenggara (Gambar 1).

\section{Pengumpulan Data}

Penelitian ini menggunakan pendekatan metode kuantitatif, konstruktivitisme yang menjadi titik tolak penelitian kualitatif. Penelitian kuantitatif diurai menjadi sejumlah jenis atau strategi penelitian, yaitu deskriptif dan survey, sedangkan penelitian kualitatif dibagi menjadi: analisis teks dan penelitian tindakan (Putra dan Hendarman, 2012).

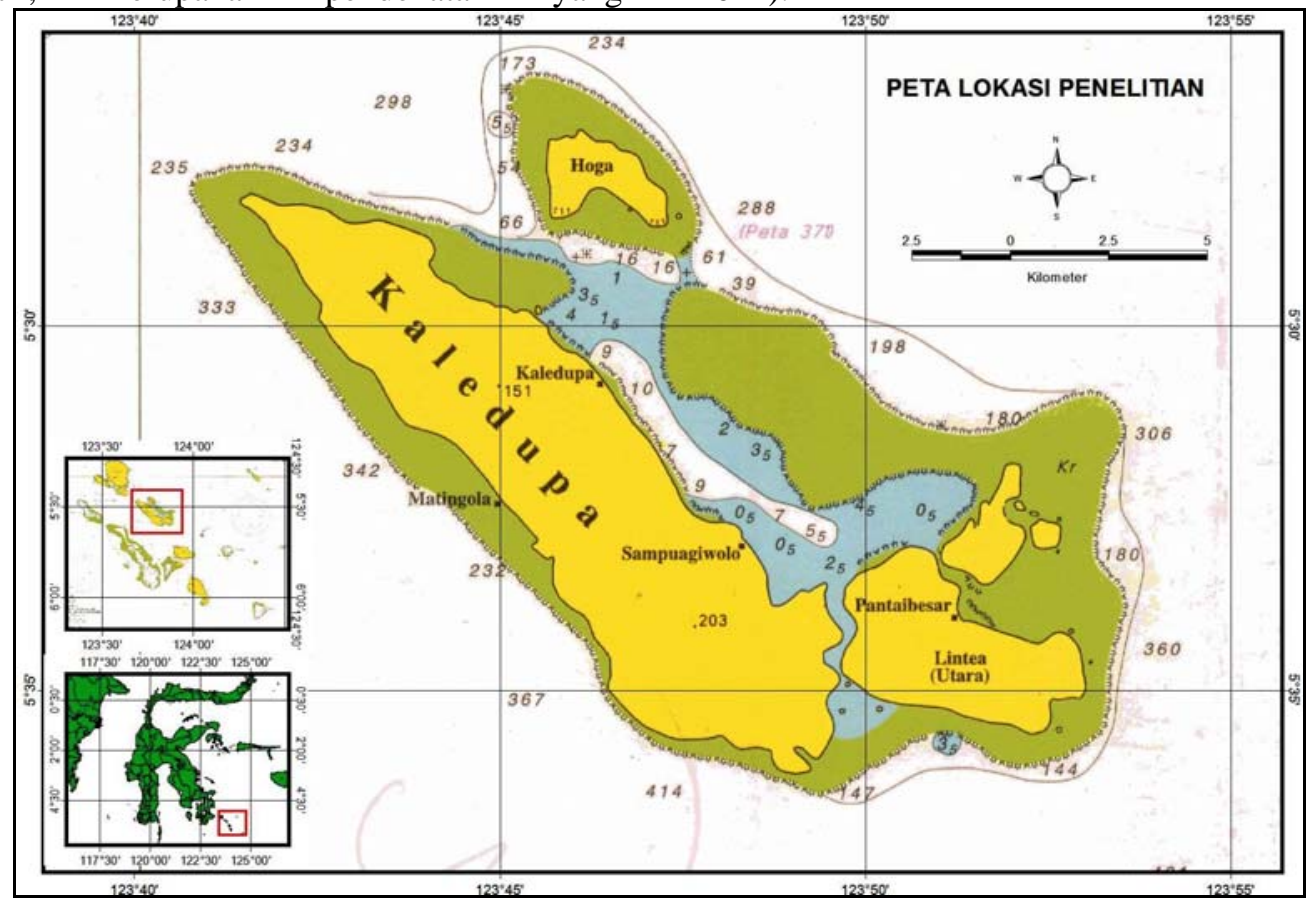

Gambar 1. Lokasi penelitian. 
Penelitian kuantitatif yang dilakukan adalah melakukan wawancara di Kecamatan Kaledupa dan Kaledupa Selatan. Responden yang diwawancarai adalah stakeholder yang berkaitan dengan pariwisata bahari secara purposive sampling (Sugiyono, 2006). Sampel meliputi: aparat permerintah daerah di antaranya aparat desa dan kecamatan, LSM, Balai Taman Nasional Wakatobi, petani rumput laut, nelayan, penyelam dan pengelola tempat wisata. Adapun materi wawancara mencakup variabel kunci yang mempengaruhi pengembangan wisata bahari. Jumlah responden di setiap wilayah antara $6-15$ orang.

\section{Analisis Data}

Penelitian ini menggunakan metode analisis prospektif partisipatif yang bertujuan untuk menghasilkan konsensus demi kepentingan perencanaan (Damai dkk., 2011). Menurut Cornwall (1995), analisis prospektif partisipatif dilakukan melalui temu pakar (expert meeting). Dalam pertemuan tersebut, pakar atau partisipan diminta untuk mengidentifikasi variabel kunci yang dianggap paling berpengaruh terhadap pengembangan pariwisata bahari di Kaledupa. Pada tahap ini ditentukan perbedaan tingkat pengaruh variabel terhadap sistem yang dikaji. Dengan demikian, dapat ditentukan variabel yang perlu diintervensi sebagai titik masuk (entry point) bagi perencanaan yang efektif (Godet dan Roubelat 1996; Bourgeois dan Jesus 2004; Gray dan Hatchard. 2008; Godet 2010 dalam Damai 2012).

Berdasarkan analisis prospektif partisipatif diperoleh skor pada pengaruh silang antar variabel yang dianalisis secara matriks (Bourgeois dan Jesus, 2004) dengan bantuan perangkat lunak Excel. Proses ini akan melihat pengaruh/ketergantungan langsung influence/dependence, (I/D) setiap variabel dengan variabel lainnya, dengan menggunakan pendekatan valuasi konsensual. Valuasi pengaruh langsung suatu variabel terhadap variabel lainnya, dengan menggunakan skala dari " 0 = tidak ada pengaruh" sampai " 3 = berpengaruh sangat kuat”. Nilai yang telah didiskusikan dan disepakati oleh partisipan, langsung dimasukkan di dalam matriks I/D. Nilai skor pengaruh silang hasil kesepakatan, secara lengkap disajikan pada tabel pengaruh. Adapun hasil analisis pengaruh antar variabel disajikan dalam bentuk grafik dan tabel.

Hasil analisis pengaruh masing-masing variabel diberi kode (huruf A sampai C), dan kondisi variabel diberi huruf kode angka (1 sampai 5). Pengembangan skenario dilakukan melalui curah pendapat (brainstorming) dan diskusi kelompok terstruktur. Partisipan diminta untuk memperkiraan kondisi masing-masing variabel penentu di masa datang. Perkiraan tersebut merupakan opini dan cerminan kebutuhan stakeholders di masa depan. Hasilnya dapat disusun skenario yang mungkin terjadi. Hasil analisis dan pembangunan skenario kemudian akan dihasilkan variabel utama dalam penyusunan kebijakan pengembangan pariwisata bahari. Variabel tersebut kemudian dibuatkan implementasi dan langkahlangkah antisipatif.

\section{HASIL DAN PEMBAHASAN}

\section{Analisis Prospektif Partisipatif}

Hasil analisis prospektif partisipatif memunculkan 18 variabel yang perlu diamati (Tabel 1). Variabel pada Tabel 1 belum diketahui variabel yang paling menentukan dalam penyusunan model pengembangan pariwisata bahari. Pengaruh antar variabel juga belum dapat digambarkan, sehingga semua variabel memiliki kepentingan dan kekuatan yang sama terhadap sistem.

\section{Analisis Pengaruh Antar-Variabel Kunci}

Hasil analisis pengaruh antar-variabel kunci menunjukkan nilai skor pengaruh silang, secara lengkap disajikan pada Lampiran 1 (tersedia dalam versi elektronik di OJS). Adapun hasil analisis pengaruh antar variabel disajikan dalam bentuk grafik dan tabel, seperti disajikan pada Gambar 2.

Pada Gambar 2. terdapat kuadran-kuadran yang masing-masing kuadran berhubungan dengan karakteristik khusus dari variabel. Kuadran I

Tabel 1. Variabel pengaruh yang diidentifikasi oleh partisipan.

\begin{tabular}{ll}
\hline No & Variabel \\
\hline 1 & Motivasi \\
2 & Karakter masyarakat \\
3 & Partisipatif \\
4 & Kolektivitas \\
5 & Perilaku masyarakat menjaga lingkungan \\
6 & Manajemen pengelolaan wisata \\
7 & Pemberdayaan masyarakat pulau kecil \\
8 & Koordinasi antar instansi \\
9 & Intermediasi \\
10 & Sejarah \\
11 & Sumber modal wisata \\
12 & Informatif \\
13 & Sarana wisata \\
14 & Pelayanan wisata \\
15 & Infrastruktur wisata \\
16 & Transportasi \\
17 & Sumber daya alam \\
18 & Sumber daya manusia \\
\hline
\end{tabular}




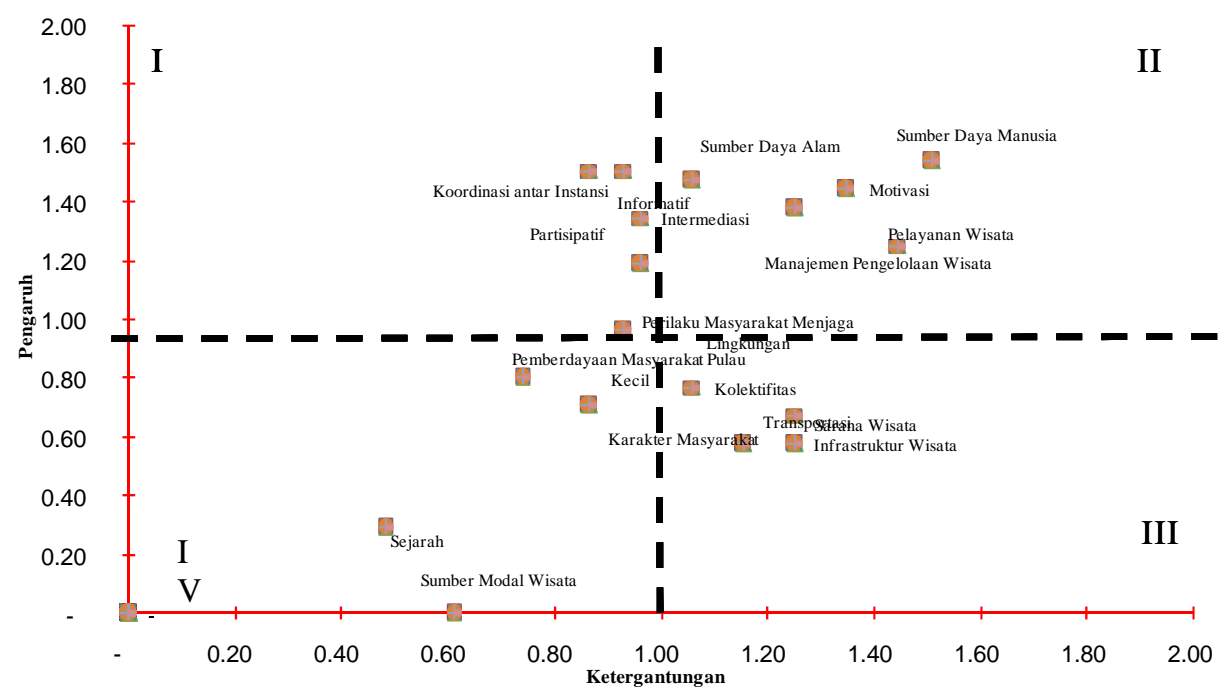

Gambar 2. Hasil analisis pengaruh langsung antar variabel.

Tabel 2. Skor kekuatan variabel global tertimbang.

\begin{tabular}{clc}
\hline No & \multicolumn{1}{c}{ Variabel } & $\begin{array}{c}\text { Kekuatan variabel } \\
\text { global tertimbang }\end{array}$ \\
\hline 1 & Informatif & 1,29 \\
2 & Koordinasi antar instansi & 1,28 \\
3 & Sumber daya alam & 1,23 \\
4 & Sumber daya manusia & 1,18 \\
5 & Intermediasi & 1,18 \\
6 & Motivasi & 1,16 \\
& Manajemen pengelolaan & \\
7 & wisata & 1,14 \\
8 & Partisipatif & 1,09 \\
9 & Pelayanan wisata & 1,04 \\
& Perilaku masyarakat menjaga & \\
10 & lingkungan & 0,98 \\
& Pemberdayaan masyarakat & \\
11 & pulau kecil & 0,91 \\
12 & Sumber modal wisata & 0,88 \\
13 & Kolektivitas & 0,85 \\
14 & Karakter masyarakat & 0,85 \\
15 & Sarana wisata & 0,77 \\
16 & Transportasi & 0,74 \\
17 & Infrastruktur wisata & 0,73 \\
18 & Sejarah & 0,69 \\
\hline
\end{tabular}

Sumber : Data primer, 2014.

merupakan wilayah variabel penggerak (driving). Kuadran II merupakan wilayah variabel kontrol (leverage), yang bercirikan pengaruh dan juga ketergantungan kuat, beberapa variabel dalam kuadran ini dapat juga digolongkan sebagai variabel kuat. Kuadran III merupakan wilayah variabel keluaran (output), yang bersifat sangat tergantung dan hanya sedikit pengaruh. Kuadran IV merupakan wilayah variabel marjinal (marginal), kelompok ini akan langsung dikeluarkan dari analisis (Damai dkk., 2011). Selain keempat kuadran, juga terdapat area abu-abu di sepanjang sumbu yang memisahkan kudran IV dari kuadran lainnya. Pada area abu-abu didapati sekelompok variabel, yang peranannya di dalam sistem tidak dapat diidentifikasi secara jelas.
Berdasarkan presentasi hasil analisis pengaruh langsung dan tidak langsung (total) yang disajikan pada Gambar 2. dapat dipilih 3 variabel yang sebagai variabel yang paling berpengaruh, yaitu informatif, koordinasi antar instansi dan sumberdaya alam. Hal ini ditunjang oleh nilai kekuatan global tertimbang masing-masing variabel, dimana 3 variabel tersebut memiliki nilai yang lebih tinggi dari lima belas variabel lainnya (Tabel 2). Dapat disimpulkan bahwa variabel nomor 1 sampai dengan 3, merupakan variabel paling berpengaruh (Godet dan Roubelat 1996; Bourgeois dan Jesus 2004).

\section{Pembangunan Skenario}

Pengembangan skenario pada Tabel 3 dilakukan melalui curah pendapat (brainstorming) dan diskusi kelompok secara terstruktur. Dalam forum tersebut, peserta diminta untuk dapat memberikan perkiraan dari kondisi masing-masing variabel penentu pada masa datang. Perkiraan tersebut merupakan opini dan cerminan kebutuhan para pemangku kepentingan di masa depan (Godet dan Roubelat 1996; Bourgeois dan Jesus 2004; Gray dan Hatchard 2008; Coates, dkk. 2010; Duranced dan Godet 2010). Dari perkiraan mengenai kondisi variabel tersebut di masa datang, dapat disusun skenario yang mungkin terjadi di Pulau Kaledupa. Skenario yang berhasil dibangun tersaji pada Tabel 3. Hasil curah pendapat partisipan dan didapat konsensus penyusunan skenario dalam penataan pariwisata bahari di Pulau Kaledupa dan sekitarnya yang mungkin terjadi adalah seperti yang disajikan pada Tabel 4 .

Berdasarkan skenario yang berhasil disusun, terlihat bahwa perbedaan antar skenario memberikan implikasi terhadap upaya yang harus dilakukan dalam pengembangan pariwisata bahari 
Tabel 3.Kondisi variabel yang ditetapkan oleh partisipan secara konsensus.

\begin{tabular}{llcccccc}
\hline & & \multicolumn{5}{c}{ Kondisi yang mungkin terjadi } \\
\cline { 3 - 8 } No. & Variabel & Kode & $\begin{array}{c}1 \\
\text { Bertambah } \\
\text { buruk }\end{array}$ & $\begin{array}{c}\text { Tetap seperti } \\
\text { sekarang }\end{array}$ & $\begin{array}{c}\text { Meningkat dengan } \\
\text { progress terbatas }\end{array}$ & $\begin{array}{c}\text { Meningkat } \\
\text { dengan baik }\end{array}$ & $\begin{array}{c}\text { Kondisi } \\
\text { ideal }\end{array}$ \\
\hline 1 & Informatif & A & A1 & A2 & A2 & A3 & A4 \\
2 & Koordinasi antar Instansi & B & B1 & B1 & B2 & B2 & B2 \\
3 & Sumberdaya alam & C & C1 & C1 & C2 & C2 & C2 \\
\hline
\end{tabular}

Sumber : Data primer, 2014.

Tabel 4. Keterangan kondisi yang mungkin terjadi.

\begin{tabular}{|c|c|c|c|}
\hline No. & Skenario & Kode & Keterangan \\
\hline 1 & Bertambah buruk & A1-B1-C1 & $\begin{array}{l}\text { A1: Tidak informatif, } \\
\text { B1: Koordinasi antar isntansi akan semakin melemah } \\
\text { C1: Sumberdaya alam semakin berkurang }\end{array}$ \\
\hline 2 & Tetap seperti sekarang & A2-B1-C1 & $\begin{array}{l}\text { A2 : Informasi yang disampaikan semakin lebih baik } \\
\text { B1: Koordinasi antar isntansi akan semakin melemah } \\
\text { C1: Sumberdaya alam semakin berkurang }\end{array}$ \\
\hline 3 & $\begin{array}{l}\text { Meningkat dengan } \\
\text { progres yang terbatas }\end{array}$ & A2-B2-C2 & $\begin{array}{l}\text { A2: Informasi yang disampaikan semakin lebih baik } \\
\text { B2: Koordinasi antar isntansi akan semakin kuat } \\
\text { C2: Sumberdaya alam tetap seperti sekarang }\end{array}$ \\
\hline 4 & Meningkat dengan baik & A3-B2-C2 & $\begin{array}{l}\text { A3: Informasi yang disampaikan semakin lebih baik diikuti dengan } \\
\text { kemudahan akses } \\
\text { B2: Koordinasi antar isntansi akan semakin kuat } \\
\text { C2: Sumberdaya alam tetap seperti sekarang }\end{array}$ \\
\hline 5 & Kondisi ideal & A4-B2-C2 & $\begin{array}{l}\text { A4: Informasi yang disampaikan semakin lebih baik diikuti } \\
\text { kemudahan akses dan telah melembaga } \\
\text { B2: Koordinasi antar isntansi akan semakin kuat } \\
\text { C2: Sumberdaya alam tetap seperti sekarang }\end{array}$ \\
\hline
\end{tabular}

Sumber : Data primer, 2014.

di Pulau Kaledupa. Pada skenario kondisi ideal, perlu dilakukan upaya perbaikan yang maksimal terhadap semua variabel sehingga kondisi akan menuju ke arah yang lebih baik di masa depan. Pada skenario yang bertambah buruk, menunjukkan bahwa jika kondisi seperti saat ini terus berlangsung, tidak adanya upaya perbaikan, maka sistem akan menjadi lebih buruk daripada kondisi saat ini.

\section{Implikasi Strategis dan Aksi Antisipatif}

Hasil analisis dan pembangunan skenario menghasilkan variabel-variabel utama yang berperan dalam penyusunan kebijakan pengembangan pariwisata bahari. Variabel-variabel tersebut diharapakan dapat meningkatkan kesejahteraan masyarakat lokal, menjamin keindahan antar generasi dan inter-generasi, melindungi keanekaragaman biologi dan mempertahankan sistem ekologi yang ada, serta menjamin integritas budaya (Moscardo dan Kim, 1990). Menurut Adrianto (2013) pendekatan pembangunan dalam implementasinya harus berbasis ekonomi biru karena akan bersinergi dengan pelaksanaan triple track strategy, yaitu program pro-poor (pengentasan kemiskinan), progrowth (pertumbuhan), pro-job (penyerapan tenaga kerja) dan pro-environment (melestarikan lingkungan). Adapun Implementasi ke tiga variabel tersebut adalah diuraikan pada bagian berikut meliputi variabel informatif, koordinasi antar instansi dan sumber daya alam.

\section{Variabel informatif}

Proses pengembangan pariwisata bahari dan pengelolaannya harus mempertimbangkan aspek informasi. Semua program pengembangan dan pengelolaan harus memberikan informasi atau pengetahuan secara eksplisit dan jelas agar tidak terjadi kesalahpahaman. Informasi yang diberikan harus edukatif, stimulatif dan persuasif bagi masyarakat agar mudah dimengerti dan diimplementasikan. Sebagai contoh informasi yang tidak informatif adalah timbulnya paradigma masyarakat akibat pemahaman yang kurang komprehensif terkait penjelasan dalam UU Nomor 5 tahun 1990 Pasal 1 yang menjelaskan bahwa Taman Nasional adalah kawasan pelestarian alam yang mempunyai ekosistem asli, dikelola dengan sistem zonasi yang dimanfaatkan untuk tujuan penelitian, ilmu pengetahuan, pendidikan, menunjang budidaya, pariwisata dan rekreasi. Dalam penafsiran sekilas masyarakat umum dengan adanya TNW akan menutup akses bagi masyarakat untuk melakukan aktivitas dalam memenuhi kebutuhan hidupnya. Akan tetapi jika mengkaji 


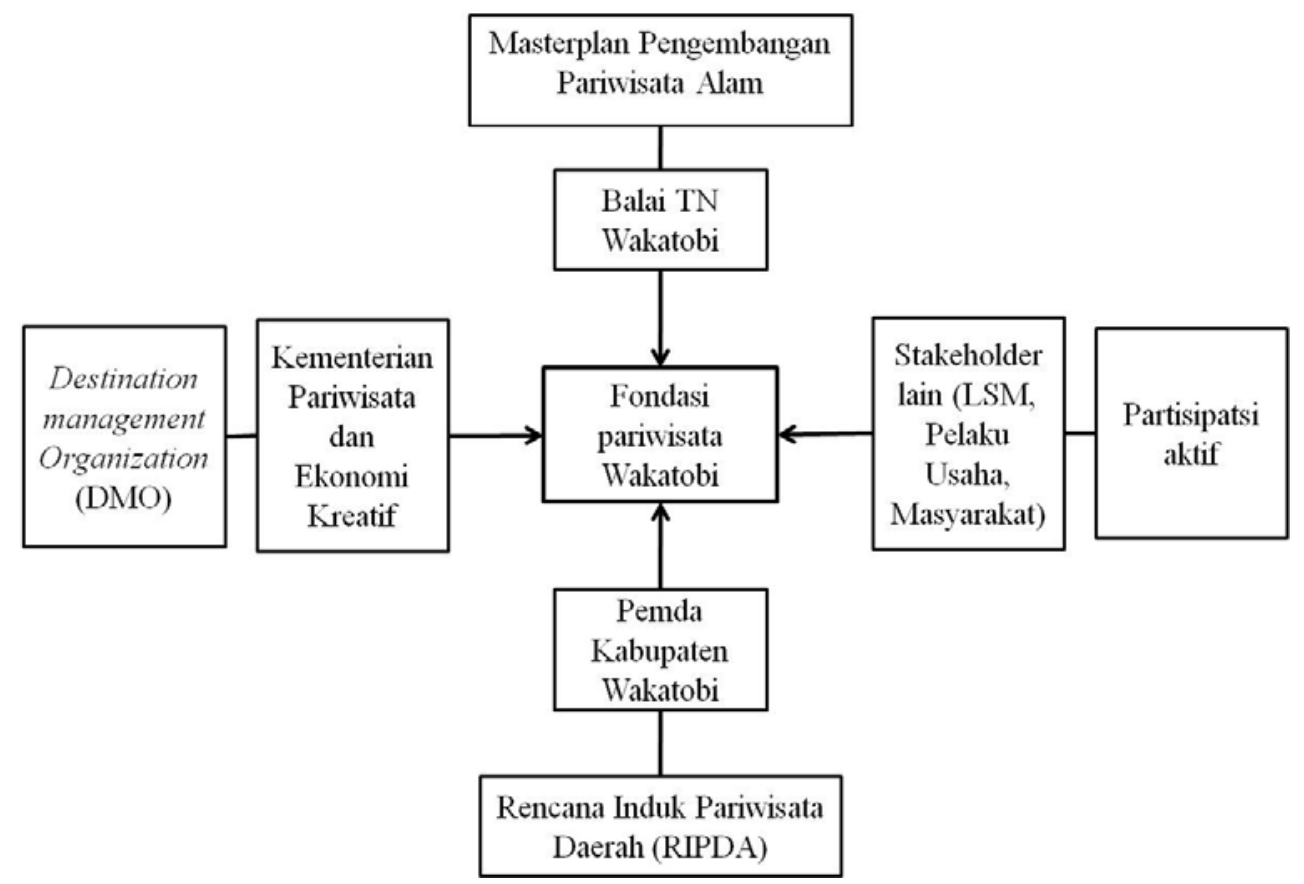

Gambar 3. Koordinasi antar instansi pariwisata bahari (modifikasi Santosa, 2013).

pasal lain terutama pasal 26 yang menjelaskan tentang pemanfaatan secara lestari sumberdaya alam hayati dan ekosistemnya, dan juga penjelasan pasal 37 tentang peran serta masyarakat. Oleh karena itu informasi yang komprehensif dan informatif dapat menunjang hubungan yang harmonis antara pengelola pariwisata dengan masyarakat. Hal tersebut seusai dengan prinsip propoor dan pro-environment.

\section{Variabel koordinasi antar instansi}

Dalam melaksanakan proses pengembangan pariwisata bahari dan pengelolaannyaharus dilakukan secara koordinasi antar instansi. Koordinasi tersebut sesuai dengan triple track strategy yaitu pro-growth (pertumbuhan), pro-job (penyerapan tenaga kerja). Pengembangan dan pengelolaan pariwisata bahari merupakan tanggung jawab semua pihak, baik itu Kementerian Pariwisata, Jaringan ekoturisme Indonesia, stakeholder taman nasional, Dinas Pariwisata, LSM misalnya TNC dan WWF, pelaku usaha pariwisata, tokoh masyarakat dan lainnya (Gambar 3). Perlu ditingkatkan upaya untuk mensinergikan perencanaan, pengembangan dan pengelolaan pariwisata. Tujuannya adalah untuk menciptakan keterpaduan pengembangan pariwisata bahari yang berkelanjutan (Hermantoro, 2009) Keberhasilan pengembangan dan pengelolaan pariwisata bahari ini dapat diukur melalui 2 indikator yaitu semakin terkelolanya tujuan pariwisata dan semakin meningkatnya kualitas tujuan dan jumlah wisatawan (Santosa, 2013). Jika kedua hal tersebut tercapai, maka koordinasi antar instansi dapat dikatakan telah berhasil, diharapkan kepuasan wisatawan, masyarakat dapat meningkat serta mampu mendorong peningkatan kesejahteraan dan kualitas lingkungan.

\section{Variabel sumberdaya alam}

Pengembangan dan pengelolaan pariwisata bahari perlu berbasis pada kesinambungan sumberdaya alam agar selaras dengan triple track strategy yaitu pro-poor (pengentasan kemiskinan), pro-growth (pertumbuhan), pro-job (penyerapan tenaga kerja) dan pro-environtment (melestarikan lingkungan). Sesuai dengan pendapat Gunn (1993) yang menyatakan bahwa suatu kawasan wisata yang baik dan berhasil bila secara optimal didasarkan salah satunya pada aspek mempertahankan kelestarian lingkungannya, termasuk sumberdaya alamnya. Perlu diperhatikan juga kemampuan daya dukungnya sehingga perencanaan secara spasial akan bermakna. Daya dukung tersebut adalah daya dukung ekologis dan daya dukung fisik. Daya dukung ekologis merupakan tingkat maksimal penggunaan suatu kawasan. Daya dukung fisik merupakan jumlah maksimum penggunaan atau kegiatan yang direkomendasikan dalam areal tersebut tanpa menyebabkan kerusakan atau penurunan kualitas.

\section{KESIMPULAN}

Berdasarkan hasil penelitian dihasilkan tiga variabel utama dalam pengembangan pariwisata 
bahari di Pulau Kaledupa yaitu variabel-variabel informatif, koordinasi antar instansi, dan sumberdaya alam. Penelitian ini menunjukkan bahwa bagi masyarakat Pulau Kaledupa ketiga variabel tersebut berperan dan perlu dikuatkan bagi pengembangan pariwisata bahari, bukan hanya memfokuskan pada pengembangan dan pembangunan infrastrukstur saja. Penguatan pada ketiga variabel tersebut diharapkan dapat mengoptimalkan peran serta masyarakat, sehingga diharapkan dapat meningkatkan kepuasan wisatawan dan kesejahteraan masyarakat Pulau Kaledupa.

\section{UCAPAN TERIMAKASIH}

Data lapangan yang digunakan dalam penelitian ini berasal dari kegiatan penelitian yang dibiayai oleh DIPA Pusat Penelitian dan Pengembangan Sumberdaya Laut dan Pesisir, Balitbang-KKP tahun anggaran 2014 nomor MAK 2373.004.013.524111. Penulis mengucapkan terima kasih kepada Dr. Budi Sulistiyo selaku Kapuslitbang SDLP dan tim kegiatan Wakatobi. Terima kasih juga diucapkan untuk Kepala Seksi 2 Taman Nasional Wakatobi, dan staf diantaranya Pak Faruli, Pak Ali dan Pak Sahari yang telah banyak membantu pelaksanaan survey lapangan.

\section{DAFTAR PUSTAKA}

Adam, L., 2012. Kebijakan Pengembangan Perikanan Berkelanjutan (Studi Kasus: Kab. Wakatobi, Provinsi Sulawesi Tenggara dan Kab. Pulau Morotai, Provinsi Maluku Utara), Jurnal Perikanan \& Kelautan, 2(2):115-126.

Adrianto, L., 2013. Bahan Presentasi Ekonomi Biru untuk Perikanan Tangkap. Institut Pertanian Bogor, Bogor.

Barus, S.I.P., Patana, P., dan Afiffudin, Y., 2013. Analisis Potensi Obyek Wisata dan Kesiapan Masyarakat dalam Pengembangan Desa Wisata Berbasis Masyarakat di Kawasan Danau Linting Kabupaten Deli Serdang. Peronema Forenstry Science Journal, 2(2):143-151.

Anonim, 2009. Kabupaten Wakatobi Dalam Angka Tahun 2009. Wanci, Wakatobi.

Bourgeois, R., dan Jesus, F., 2004. Participatory Prospective Analysis: Exploring and Anticipating Challenges with Stakeholders. CAPSA Monograph No. 46, Bogor.

Cornwall, A., dan Jewkes. R., 1995. What is Participatory Research? Soc. Sci. Med. 41(12):1667-1676.
Coates, J., Durance, P., dan Godet, M., 2010. Strategic Foresight Issue: Introduction. Technol. Forecas. Soc. Change, 77:1423-1425.

Damai, A, Boer, M., Marimin, Damar, A., dan Rustiadi, E., 2011. Analisis Prospektif Partisipatif dalam Pengelolaan Wilayah Pesisir Teluk Lampung. Forum Pascasarjana, 34(4): 281-296.

Damai, A,A., 2012. Sistem Perencanaan Tata Ruang Wilayah Pesisir: Studi Kasus Teluk Lampung [Disertasi] Sekolah Pasca Sarjana Institut Pertanian Bogor, Bogor.

Durance, P., dan Godet, M., 2010. Scenario Building: Uses and abuses. Technol. Forecas. Soc. Change 77:1488-1492.

Febriani, N.D., 2011. Perencanaan Program Ekowisata Mangrove di Pulau Kaledupa Taman Nasional Wakatobi, Tugas Akhir, Program Keahlian Ekowisata, Program Diploma Institut Pertanian Bogor, Bogor.

Godet, M., dan Roubelat, F., 1996. Creating the Future: The Use and Misuse of Scenarios. Long Range Plann. 29 (2):164-171.

Gray, T., dan Hatchard, J., 2008. A Complicated Relationship: Stakeholder Participation and the Ecosystem-Based Approach to Fisheries Management. Marine Policy, 32(2):158-168.

Gunn, C.A, 1993, Tourism Planning: Basics, Concepts, Cases. Taylor \& Francis, New York.

Harun, Z., 2014, Model Strategi Pemberdayaan Masyarakat Melalui Pengembangan Pariwisata yang Berbasis Komunitas Lokal : Kasus di Kota Padang Panjang, Jurnal Antropologi, 16(1):99-106.

Hermantoro, H., 2009, Pengelolaan Bidang Pariwisata Bahari dalam Pelaksanaan Strategi Adaptasi Terhadap Dampak Perubahan Iklim, Jurnal Kepariwisataan Indonesia, 4(1):142158.

Moscardo, G., dan Kim, E., 1990, Social Science Research Need for a Sustainable Coastal and Marine Tourism, CRC Reef Research Center, James Cook University, Townsville.

Nugraha, P,S., dan Aliyah, I., 2013, Pengelolaan Kawasan Wisata Berbasis Masyarakat Sebagai Upaya Penguatan Ekonomi Lokal dan Pelestarian Sumberdaya Alam di Kabupaten Karanganyar, Jurnal Cakra Wisata, 13(1):2638.

Putra, N., dan Hendarman, 2012, Metodologi Penelitian Kebijakan. Penerbit PT. Remaja Rosdakarya, Bandung.

Santosa, H., 2013, Harmonisasi Pariwisata Berkelanjutan Wakatobi Melalui Program 
Destinastion Management Organization (DMO), Buletin Napoleon, 3:1-4.

Sugiyono, 2006, Metode Penelitian Kuantitatif, Kualitatif, dan $R$ \& $D$. edisi ke-2, CV Alfabeta, Bandung.

Sukadi, Sutama dan Sanjaya, 2013, Pengembangan Potensi Pariwisata Spiritual Berbasis
Masyarakat Lokal di Bali, Jurnal Ilmu Sosial \& Humaniora, 2(1):150-157.

Tanaya, D,R., dan Rudiarto, I., 2014, Potensi Pengembangan Ekowisata Berbasis Masyarakat di Kawasan Rawa Pening, Kabupaten Semarang, Jurnal Teknik PWK., 3(1):71-81. 